\title{
Real Time Simulation of Direct Torque Control of BLDC Motor Drive using Opal-RT Simulator
}

\author{
Kaushal B. Sontakke ${ }^{1}$, Dr. Ramchandra P. Hasabe ${ }^{2}$ \\ ${ }^{1}$ Department of Electrical Engg., Walchand College Engg. Sangli \\ ${ }^{2}$ Department of Electrical Engg.,Walchand College Engg. Sangli
}

\begin{abstract}
This paper presents real time simulation of direct torque control of Brushless DC motor drive using Opal-RT simulator. The BLDC motor which is not having brushes has minimum losses which can be largely used in industries. The control of BLDC based upon various conventional methods which are used to control of ac machines.

In this paper the mathematical model of BLDC Motor and torque control method used is based upon position of rotor which gives proper orientation of rotor, this signal is gives to controller which again gives to selecting switching table, again by proper selection of switching the signal is send to 3 phase inverter which then rotates the motor and torque control can be achieved.

Also the real time simulation can be achieved by using Opal-RT simulator OP-4501 the simulation results and real time results are obtained by using FPGA card and at time step.

Index Terms:- Brushless DC motor, direct torque control, torque ripple, switching frequencies, common mode voltage, real time simulation, OPAL-RT Simulator.
\end{abstract}

\section{INTRODUCTION}

In recent years, variable speed drives equipped with BLDC motors are extensively integrated into various applications ranging from servos to traction drives. Compared to BLAC it is relatively low cost. Since it has shorter end windings and does not require precision position sensor encoders. Therefore, in general, BLDC Drives are relatively low cost, the main advantages of the BLDC motors can be listed as follows: Low Noise, Low inertia High efficiency, High power density, more starting torque, Large speed ranges, speed, and torque characteristics are linear,

They operate in any condition and having minimum maintenance.

In between the control strategies that exhibit a high torque dynamic, the DTC method is mostly used for induction motor drives. The direct control is achieved by inverter switching pattern for control of electromagnetic torque and stator flux. Conventionally speed control of BLDC drive is doing hysteresis controller. But recently DTC has been employed for the BLDC drive. In DTC relationship is established between the torque responses. It gets better dynamic performance than conventional control methods that are less sensitive to parameter variations and simpler to implement. Electric vehicles have recently received many attentions from researchers due to their advantages over the conventional use of non-renewable sources. Electric Vehicle reduces the pollution that subsidies to climate change and smog, improving public health and reducing ecological damage.

\section{BLOCK DIAGRAM OF TOPOLOGY}

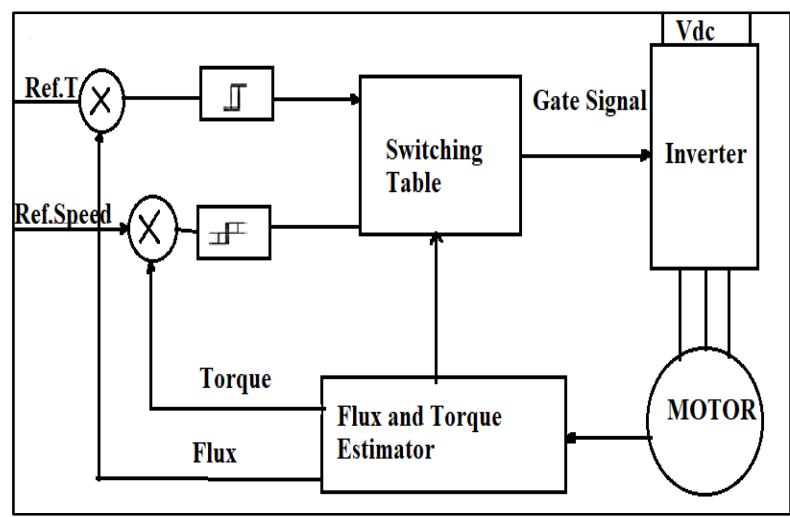

Figure1 DTC control of the BLDC motor Drive.

The block diagram for DTC control of BLDC motor Drive is as shown in Figure1. From the BLDC motor flux and torque reference is taken, that is compared with estimated value of torque and flux depending upon this hysteresis controller applied the parameter for voltage space vectors that are applied to BLDC motor with the help of inverter and estimated flux here voltage space vectors that are being applied to BLDC motor. By selection of voltage vectors flux trajectory i.e. circle or hexagon is produced. (In this technique conditions of intensity switches are resolved straightforwardly by the determined and reference torque and transition signals. This is accomplished by utilizing exchanging table. The contribution of which are torque, stator motion blunder and stator transition determined mistake which is isolated into six parts of 60 degrees)

The switching table output is applied to inverter which is depends on the error signals.

For energy saving in industry there is increase in use of variable speed drives. Initially direct current machines are control by decoupled nature of flux and torque then field oriented control and DTC methods are developed. Also these methods then used for control of ac machines. In field oriented control method current controller and ability to know just sector in which stator flux linkage space vector is varied rather exact position of vectors. In DTC the current controller 
is absent. The pain principle of DTC is to calculate instantaneous torque parameter depends on stator flux vectors,

$$
\begin{gathered}
\psi_{\mathrm{as}}=\int\left(\mathrm{V}_{\mathrm{as}}-\mathrm{R}_{\mathrm{as}} \mathrm{i}_{\mathrm{as}}\right) \mathrm{dt} \\
\Psi_{\beta \mathrm{s}}=\int\left(\mathrm{V}_{\beta \mathrm{s}}-\mathrm{R}_{\beta \mathrm{s}} \mathrm{i}_{\mathrm{ss}}\right) \mathrm{dt} \\
\mathrm{T}=\frac{3}{2} \frac{\mathrm{P}}{2}\left(\frac{\left.\mathrm{d} \Psi_{\mathrm{ra}} \mathrm{i}_{\mathrm{sa}}+\frac{\mathrm{d} \Psi_{\mathrm{r} \beta}}{\mathrm{d} \theta_{\mathrm{e}}} \mathrm{i}_{\mathrm{s} \beta}\right)}{\mathrm{d} \mathrm{e}_{\mathrm{e}}}\right.
\end{gathered}
$$

Where, $\mathrm{p}=$ pole pair,

$\theta_{\mathrm{e}}=$ Electrical rotor angle,

Ls $=$ Stator coils inductance

$i_{s \alpha}$ and $i_{s \beta}$ are stator current of $\alpha$ and $\beta$ axis

$\psi_{\mathrm{r}}$ and $\psi_{\mathrm{r}}$ are $\alpha$ and $\beta$ stator and rotor flux linkage respectively. The stator space vectors are Therefore change in switching instant is determined by the equation as

$$
\psi_{\mathrm{s}}=\frac{1}{\mathrm{~T}_{\mathrm{n}} \int_{0}^{\mathrm{t}} \mathrm{V}_{\mathrm{s}} \mathrm{dt}}
$$

In BLDC motor, when forward active voltage vectors are applied then stator flux linkage vectors moved away from rotor flux vector. This is increases the torque parameter because of torque angle increases. This means that when zero or backward active voltage space vectors are applied then torque angle is decreases. The current and voltage is converted into park's transformation which is used to calculate stator flux linkage is given by equations.

Voltage and current equations wrt to stationary frame of reference.

$\left[V_{a} V_{b} V_{c}\right]=[2 / 3-1 / 30-1 / \sqrt{3}][$ VsaVs $\beta]$
$\left[I_{a} I_{b} I_{d}\right]=[2 / 3-1 / 30-1 / \sqrt{3}]\left[I_{s a} I_{s \beta}\right]$

Stator Flux Linkages:

$$
\begin{aligned}
& \Psi_{s a}=V_{s a}-I_{s a} R_{s} \\
& \Psi_{s \beta}=V_{s \beta}-I_{s \beta} R_{s}
\end{aligned}
$$

Rotor flux linkages and position estimator, stator flux linkage position helps to determined variation of vectors within trajectory which is evaluated by following equations: Rotor flux linkage:

$$
\begin{gathered}
\Psi_{R a}=\Psi_{s a}-L_{s} i_{s a} \\
\Psi_{R \beta}=\Psi_{s \beta}-L_{s} i_{s \beta} \\
\Psi_{R \beta}=\Psi_{s p}-L_{s} i_{s \beta} \quad \Psi_{R p}=\Psi_{s \beta}-L_{s} i_{s \beta} \\
\Psi_{R \beta}=\Psi_{s \beta}-L_{s} i_{s \beta}
\end{gathered}
$$

And its position in $\alpha-\beta$ stationary reference frame is given by Position Estimator:

$$
\theta_{\mathrm{e}}=\left(\frac{\Psi_{\mathrm{s} \beta-\mathrm{L}_{\mathrm{s}} \mathrm{i}_{\mathrm{ip}}}}{\Psi_{\mathrm{sa}}-\mathrm{L}_{\mathrm{s}} \mathrm{i}_{\mathrm{sa}}}\right)
$$

Stator flux linkage Position:

Where,

$$
\theta_{s}=\left(\frac{\Psi_{s g}}{\Psi_{s a}}\right) \theta_{s}=\left(\frac{\Psi_{s B}}{\Psi_{s a}}\right) \theta_{S}=\left(\frac{\Psi_{S \beta}}{\Psi_{S a}}\right)
$$

$\psi_{\mathrm{s} \alpha} \psi_{\mathrm{s} \beta}=$ stator flux linkages wrt to $\alpha$ and $\beta$ axis, $\theta_{\mathrm{e}}=$ rotor position estimator

$\theta_{\mathrm{s}}=$ stator flux linkage position.

Evaluated parameters are compared in two levels and three level flux and torque comparator. Results generated is fed up to inverter circuit with applied voltage, switching voltage is given as,

$V_{s a}=\frac{2}{3} V_{a}-\frac{1}{3} V_{b}-\frac{1}{3} V_{c}$

$\mathrm{V}_{\mathrm{sb}}=\frac{2}{3} \mathrm{~V}_{\mathrm{b}}-\frac{1}{3} \mathrm{~V}_{\mathrm{a}}-\frac{1}{3} \mathrm{~V}_{\mathrm{c}}$

$V_{s c}=\frac{2}{3} V_{c}-\frac{1}{3} V_{b}-\frac{1}{3} V_{a}$

Switching table for DTC of BLDC drive is as shown in Table 4.1,

Table I. Voltage space vectors

\begin{tabular}{|l|l|c|c|c|c|c|c|}
\hline Torque & Flux & \multicolumn{3}{|l|}{ Sectors } \\
\cline { 3 - 8 } & & I & II & III & IV & V & VI \\
\hline \multirow{4}{*}{1} & 1 & V1 & V2 & V3 & V4 & V5 & V6 \\
\cline { 2 - 8 } & 0 & V2 & V3 & V4 & V5 & V6 & V1 \\
\cline { 2 - 8 } & -1 & V3 & V4 & V5 & V6 & V1 & V2 \\
\hline 0 & 1 & V1 & V2 & V3 & V4 & V5 & V6 \\
\cline { 2 - 8 } & 0 & V0 & V0 & V0 & V0 & V0 & V0 \\
\cline { 2 - 8 } & -1 & V3 & V4 & V5 & V6 & V1 & V2 \\
\hline
\end{tabular}

There are a few special features of DTC control that can be summarized as follows:

- No feedback current control

- No traditional PWMalgorithm is applied

- No vector transformation as in vector control

- Feedback signal processing is somewhat similar to stator flux-oriented vector control

- Hysteresis-band control generates flux and torque ripple and switching frequency is not constant (like hysteresis-band current control)

\section{SIMULATION AND SIMULATION RESULTS}

\section{A. Simulation of Direct Torque control of BLDC motor drive}

The simulation model for DTC of BLDC motor drive is shown in figure. The overall system consists of two loops for torque and stator flux. The stator flux and torque thai is reference value is compared with actual value taken from motor stationary reference frame model and from this errors are calculated for analysis. The errors then given to hysteresis current controller, depending upon this from current controller results are combining with position of stator flux and it making switching selection table.

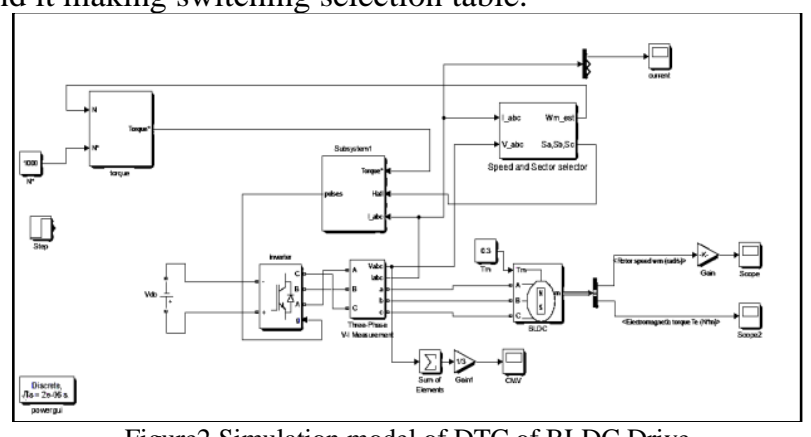

Figure2 Simulation model of DTC of BLDC Drive 
The DTC method requires calculation of stator flux and torque which are obtained by two different phase current and state of an inverter as in Figure 6

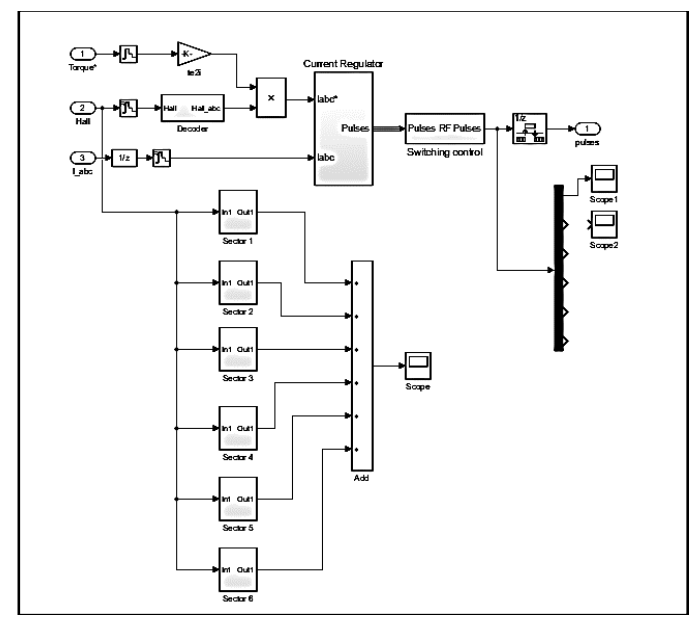

Figure 3 Simulation model for sector Successions and gate pulse generation

As transistors in inverter are switched to keep toque and flux with their hysteresis band, due to this switching losses are relatively low.

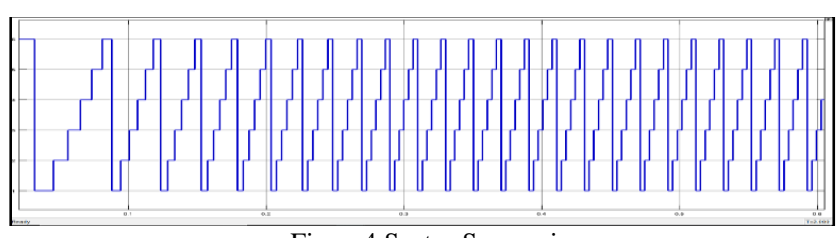

Figure4 Sector Successions

Figure 4 shows sector succession and Figure 5 shows gate pulse generated which is fed to inverter generated by considering current, torque and hall sensor signal.

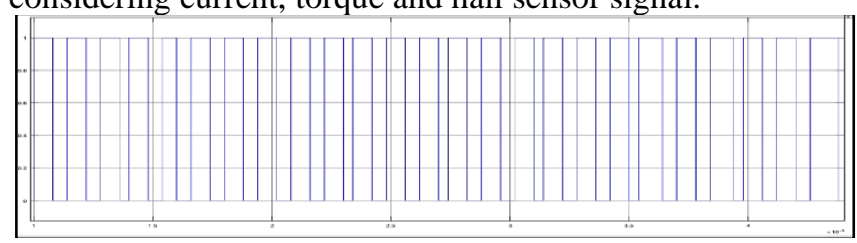

Figure 5 Gate pulse generated

Here, Figure 6 shows that the torque is estimated from reference speed and actual speed which is calculated as shown in simulation model (Figure 6)

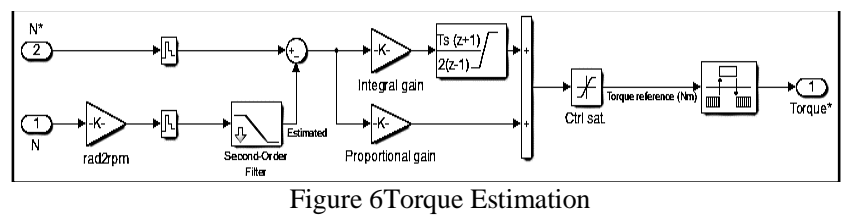

igureure.7 Simulation model for Reference speed generation. The back emf is calculate from the formula where $e_{a}, e_{b}$ and $e_{c}$ are back emf's as shown in Figure 8

$$
v_{a}=R_{s} i_{a}+L_{s} \frac{d i_{a}}{d t}+e_{a} v_{b}=R_{s} i_{b}+L_{s} \frac{d i_{b}}{d t}+e_{b} v_{c}=R_{s} i_{c}+L_{s} \frac{d i_{c}}{d t}+e_{c}
$$

Figure 8 Simulation model for Back emf.
Where $e_{a}, e_{b}$ and $e_{c}$ are back emf's which is simulated in model as,

From back emf the abc reference coordinate is converted into alpha-beta reference frame for calculation of alpha from given i.e. rotor angle Figure 9 again speed is calculated to torque estimation then pulses are generated which is fed to inverter.

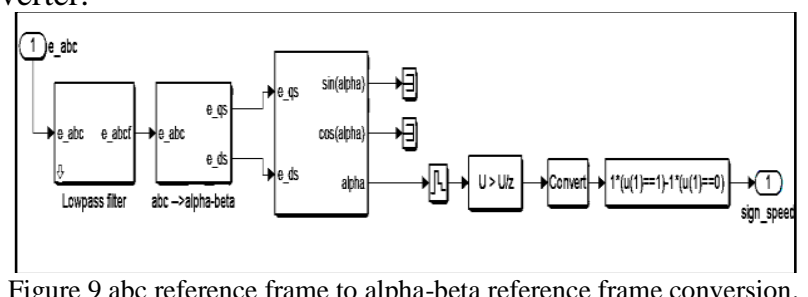

Figure 9 abc reference frame to alpha-beta reference frame conversion.

Following Figure 10-12 shows the simulation results corresponding to the steady-state operation of the BLDC motor under the proposed DTC. The waveforms show the electromagnetic torque, common mode voltage and phase currents. The Figure5.9 Shows Torque/time characteristics of BLDC motor with no load, as the speed reaches to its steady state position the torque remain constant.

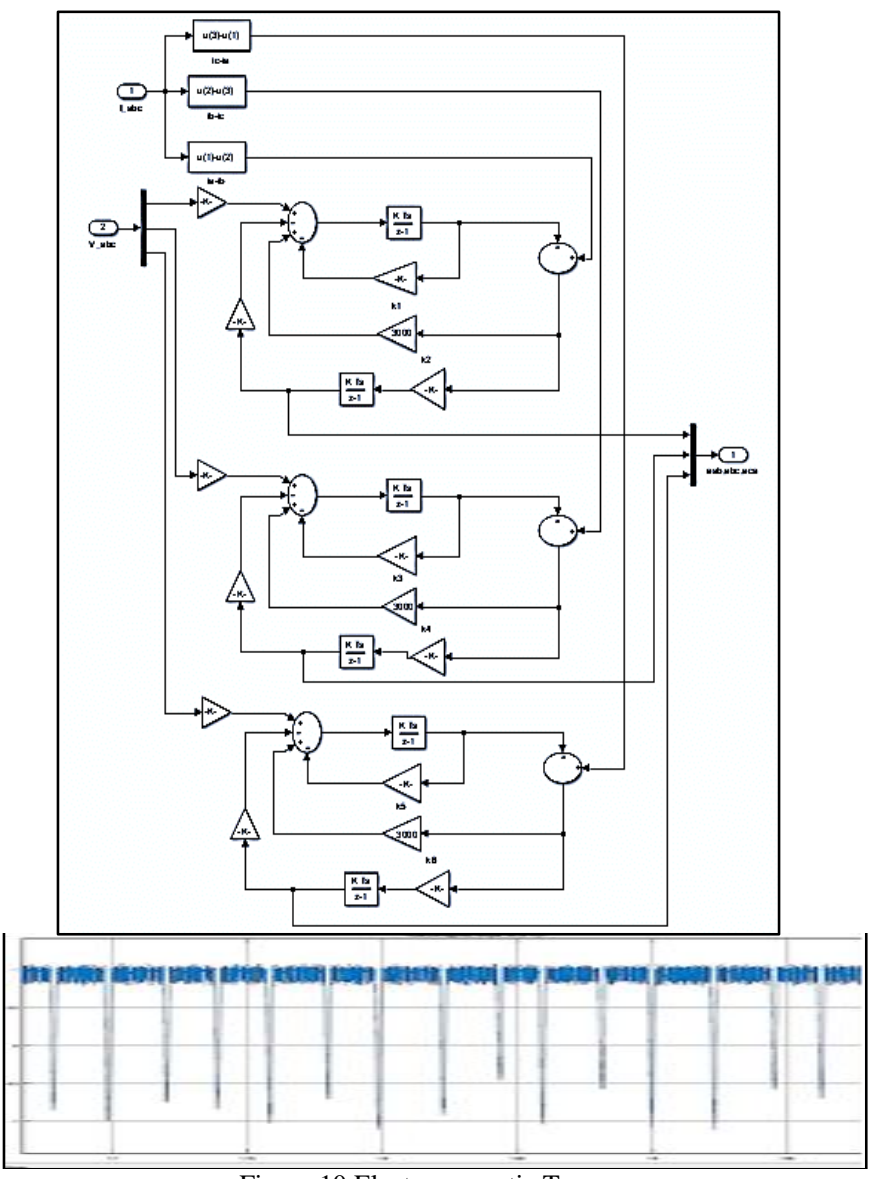

Figure 10 Electromagnetic Torque

Moreover, Figure 5.10 shows that the CMV average value is almost null. CMV is given as,

$$
\mathrm{CMV}=\frac{\mathrm{va}_{\mathrm{a}}+\mathrm{v}_{\mathrm{b}}+\mathrm{v}_{\mathrm{c}}}{3}
$$




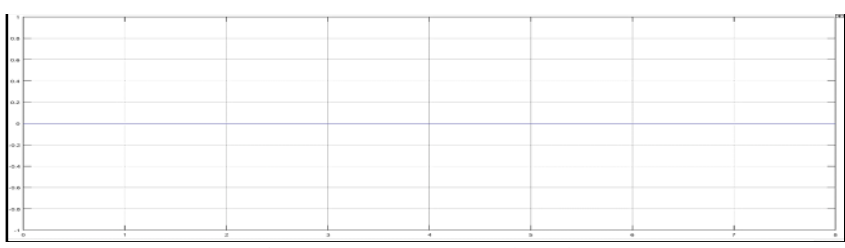

Figure11 Common mode voltage

Phase currents are sinusoidal in nature and there is phase difference of 120 degrees between each other. Phase current waveforms for three phase BLDC motor is as shown in Figure5.11.

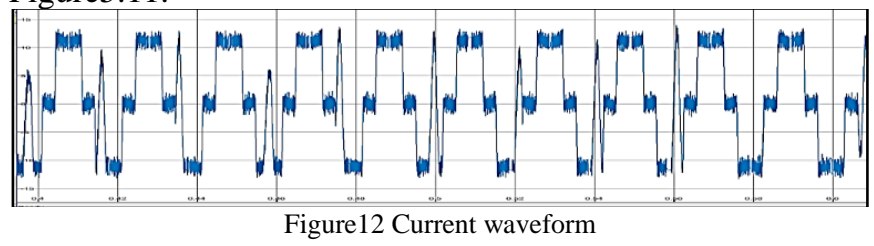

information about the speed control of the BLDC motor for various applications.

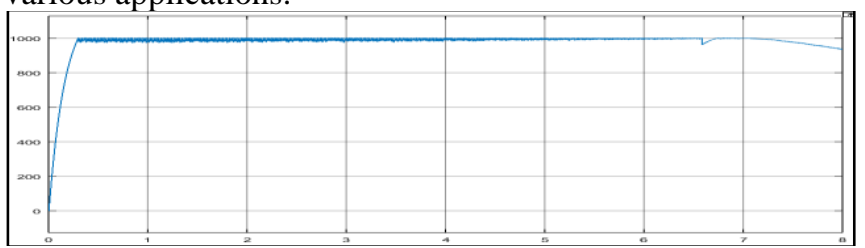

Figure 13 Rotor Speed

The parameters of the BLDC motor, which are considered in the simulation, are

$\begin{array}{ll}\text { Pole Pair no } & 3 \\ \text { Phase Resistance } & 0.2 \mathrm{ohm} \\ \text { Self-inductance } & 0.3 \mathrm{mH} \\ \text { PM flux-linkage } & 0.3 \mathrm{~Wb}\end{array}$

\section{B. REAL TIME SIMULATION}

Digital simulators are evolved from analog simulator as simulation tools in past decades. It is carried out by using modern computer technologies it requires less cost and increases the performance. Now a day, the digital simulators are used widely in a number of industries because of it can be used virtually and there is no need for hardware prototype. The results are calculated before applying to real hardware model. In the real-time simulation, it depends on automatic code generation. Which played a very important role in many engineering field and applications, such as industrial motor drive design, power grid statistical protection tests and complex robotic controller design? From the last three decades' real-time simulators are used in power system and electrical drives.

Simulation has major role in development of layout of power system transmission to motor drive optimization and plays critical role for large number of application.
As the power system is a highly complex system also it is highly nonlinear in nature. By using a sophisticated controller, it is very complicated to run the system. So that the real-time simulation gives many advantages. The advantages of using real-time simulation are as:

1. Reduces the time

2. Cost reduction

3. Increases complexity and flexibility

4. Reduces Risks

In 1997 Jean Bélanger \& LiseLaforce founded OPAL-RT Technologies. In earlier it used in Canada arm and Canada Space Agency. Then it is used, in power grid simulators, electrical vehicles. After few years in 2016 the OP4200 simulator for power electronics, electric drive and other real-time applications.

OP4510 RT-Lab Simulator, provided by OPAL-RT Technologies. The host $\mathrm{PC}$ is generating the real time executables codes also it modifies the real timeparameters and record the data received from simuFatgurreTh 3 kbotwBCthondo load $\mathrm{sp}$ simulator are connected viaEthernet-Lan connection as shown in Figure 14 Figure14. RT-LAB Simulator (OP4510) with host Computeris used to support the real-time realization of the complicated combined system. The host PC is generating the real time executables codes also it modifies the real time parameters and record the data received from simulator. The host PC and simulator are connected via Ethernet-Lan connection as shown in Figure 14

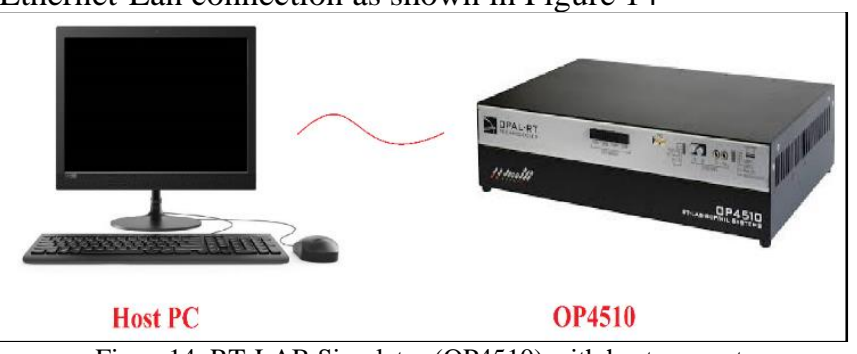

Figure 14. RT-LAB Simulator (OP4510) with host computer

To run the simulink model with OPAL-RT software and hardware the following main steps has to be follow:

1. Open the model

2. Edit the model in MATLAB

3. Compilation

4. Assign nodes

5. Synchronization Mode

6. Loading

7. Execution

8. Reset

The OPAL-RT used in following Field, Electrical Power Systems, Electrical Power Electronics, Aerospace \&Defence, Automotive, Academic \& Research.

C.REAL TIME IMPLEMENTATION FOR DIRECT TORQUE CONTROL OF BLDC MOTOR DRIVE

\section{Software Synchronization}

The MATLAB simulation diagram for DTC of BLDC motor drive is shown in Figure 15 to run this simulation model into 
real time simulator here we have to transform the simulation in two subsystems i.e. SM Main and SC Console as shown in Figure 15
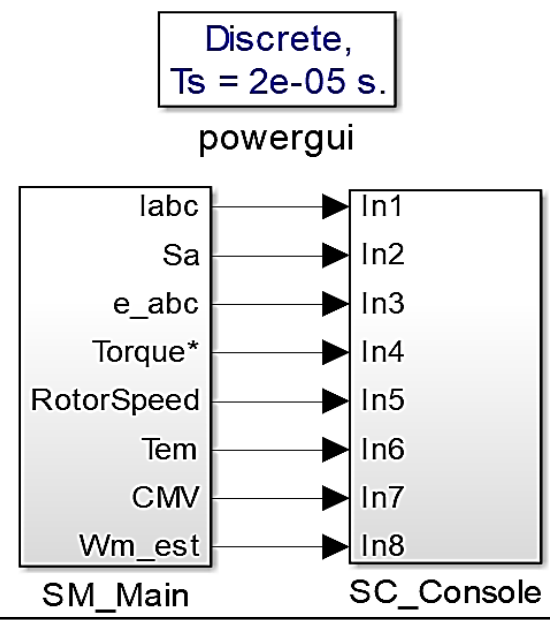

Figure 15 Complete Real time Simulink Model of DTC of BLDC Drive

SM_Main subsystem consist of main simulation model input output blocks, pulse generators, torque estimation block, speed and sector selector block as shown in Figure16 SC_Console subsystem consist of user interface blocks like scope, display, etc as shown in Figure 17 Console subsystem is available for the user while the simulation model is running. In the subsystem OpComm block is used for the communication purpose between master subsystem and console subsystem.

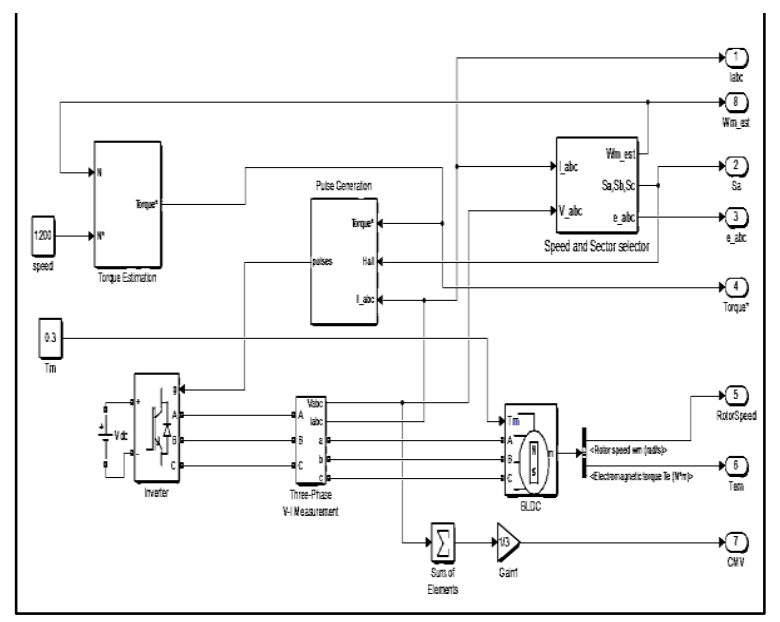

Figure16 Master Subsystem of Real time Simulink

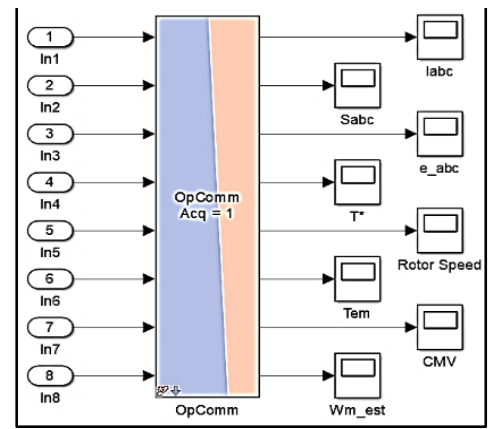

Figure17 Console Subsystem of Real Time Simulink

The RT-Lab generated SC_Console block is shown in Figure 18 below it is running in RT-Lab simulator which is generated after the following through execution steps.SC Console consists of various scopes.

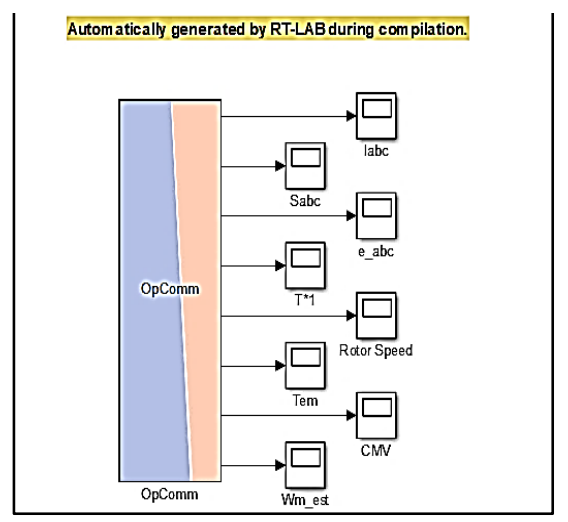

Figure18 RT-Lab generated SC_Console block

\section{Real Time Simulation Results:}

These are the results are obtained using Opal RT-Lab of DTC of brushless DC drive at Speed 1500rpm and Torque $0.5 \mathrm{Nm}$ are as, the following Figure19 shows stator phase current of BLDC motor. The phase current is seen on graph is only phase-a current.

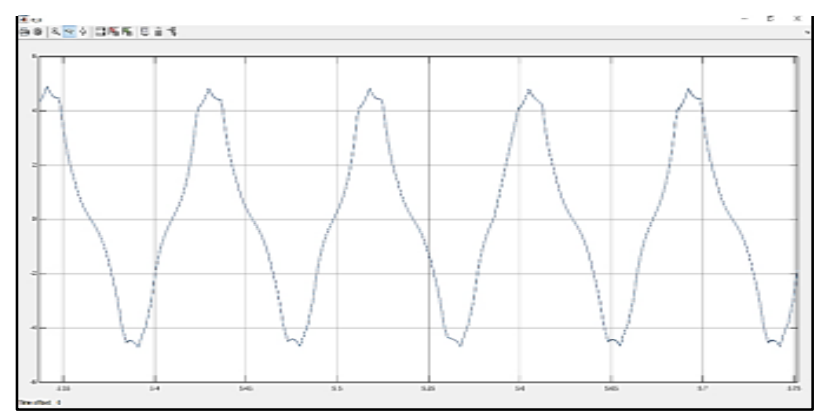

Figure19 Phase current of BLDC motor. Figure20 Back emf generated by motor.

The motor generates back emf shows inFigure 20 which is used for calculation of estimated speed. The back emfe ${ }_{a}$ is seen on graph with respect to time. The switching pattern generated by hysteresis controller by referring value of torque, phase currents and position of rotor is seen in graph as shown in Figure21, the switching pattern shown is only for phase-a i.e. for one leg of inverter, which is then runs the BLDC motor.

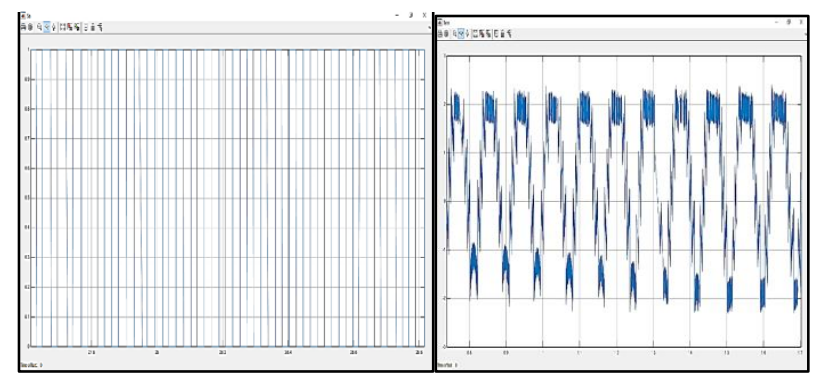

Figure21 Switching pattern Figure 22 Electromechanical Torque

The electromechanical torque of BLDC motor is shown in Figure 22.The Figure 23 Shows common mode voltage, which is calculated as, 


$$
\mathrm{CMV}=\frac{\mathrm{v}_{\mathrm{a}}+\mathrm{v}_{\mathrm{b}}+\mathrm{V}_{\mathrm{c}}}{3}
$$

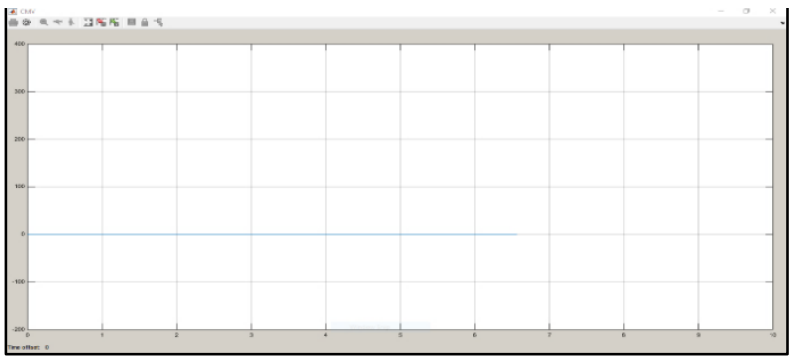

Figure23 Common mode voltage

\section{Hardware Synchronization:}

In hardware synchronization is done on an external hardware timer. For this some blocks are added insoftware synchronize model ie. OpCtrl, Opwrite and Anlog-out,as we using analog output signalwhich has to be given to the I/O port type board(TE0741).It is then given to the OPAL-RT throughconnectors. OpCtrl block is used to set the simulation state on the card. Opcomm block specifies communication between master and console subsystem. Analog out block sends analog signals to targetsimulator by using board TE0741.The Figure24 shows complete simulation diagram for hardware synchronizationof DTC of BLDC motor drive.

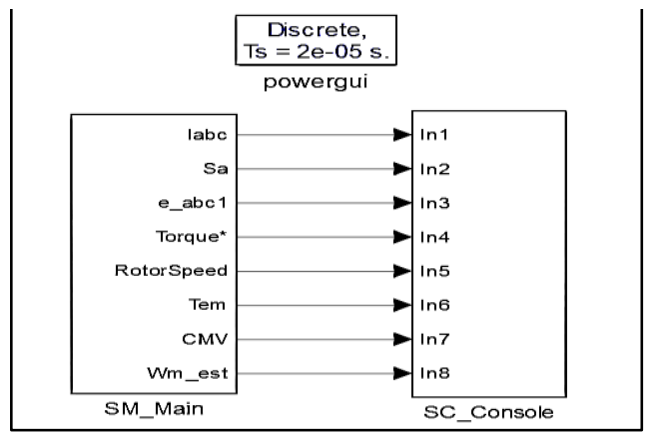

Figure24 Simulation diagram of Hardware synchronized Model

The SC_Main subsystem for hardware synchronized model is shown in Figure25 below which has main simulation model, OpCtrl block, OpWrite block and AnalogOut Block. TheSC_Main subsystem for hardware synchronized model is shown in Figure25 below which has mainsimulation model, OpCtrl block, OpWrite block and AnalogOut Block.Figure25 SM_Main subsystem ofhardware synchronized model

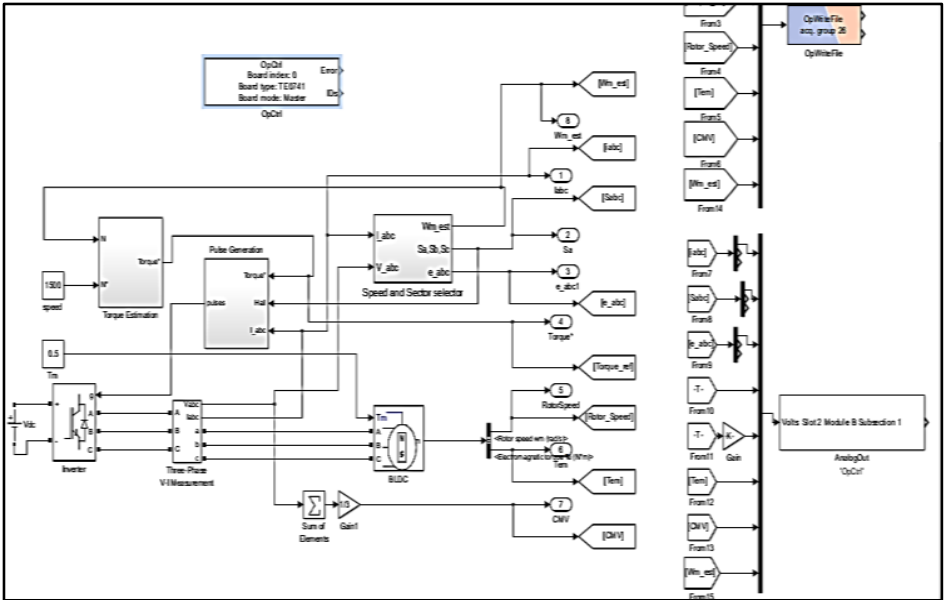

Figure25 SM_Main subsystem of hardware synchronized model

The SC_Console subsystem and RT-lab generated console subsystem is shown in Figure16 and Figure17 respectively.

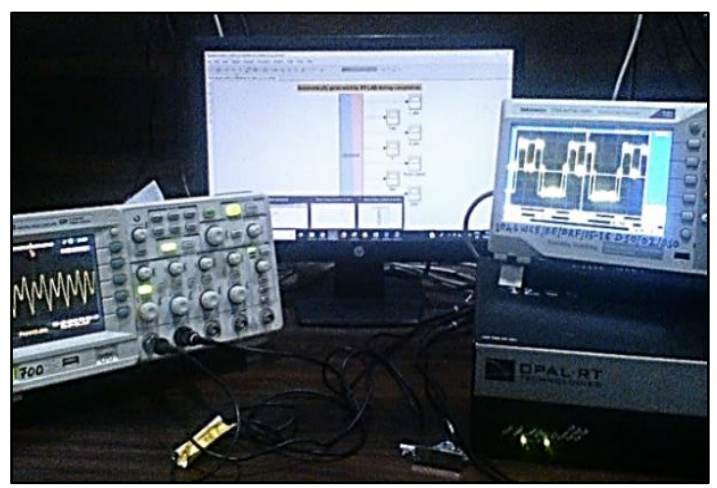

Figure26. The Overall system

The Figure 26 shows overall system which having host computer, OPAL-RT simulator and the output is seen on digital oscilloscope.

The SC Console subsystem and RT-lab generated console subsystem is shown in Figure16 and Figure17respectively. Figure26 the Overall system The Figure26 shows overall system which having host computer, OPAL-RT simulator and the output is seen on digital oscilloscope.

The output waveforms on digital oscilloscope are shown in following Figurers. The waveform for phase current (Ia) is shown in Figure27 and Figure28 shows switching for phasea.

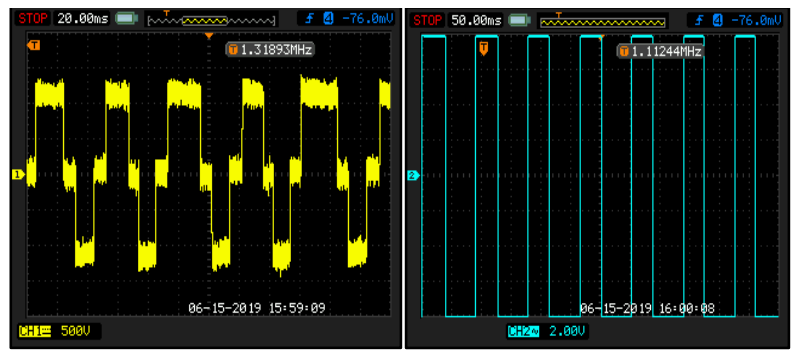

Figure.27 Phase-a Current (Ia). Figure28 Switching for phase-a. 


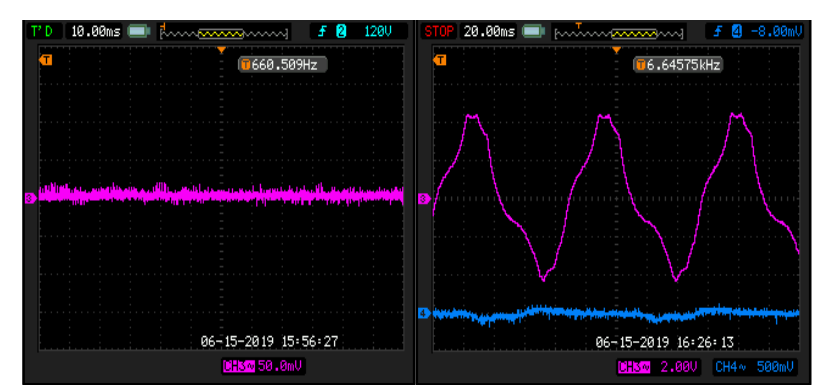

Figure 29 Common mode voltage. Figure 30 Back-emf $\left(\mathrm{e}_{\mathrm{a}}\right)$

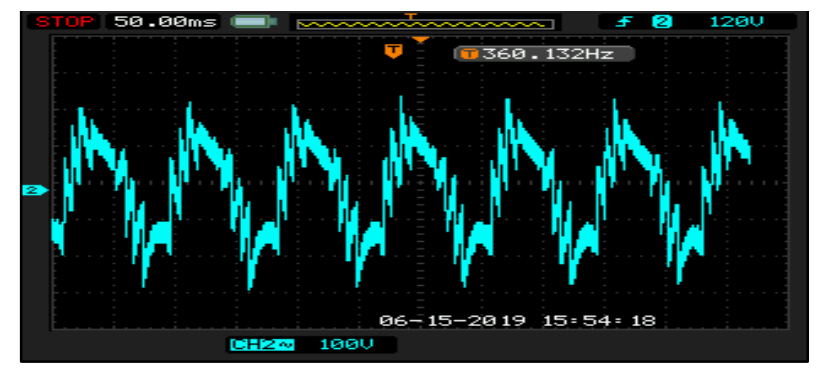

Figure31 Electromagnetic Torque

\section{CONCLUSION}

In DTC method, between estimated and actual values of flux and torque has error, for reducing the torque and speed errors we have to control different state of inverter is possible. With comparison with other conventional methods, this method minimizes steady stateerrors by controlling estimated torque of highperformance motor drive. Also the real time simulation is performed using OPAL-RT Figure.30 Back-emf $\left(\mathrm{e}_{\mathrm{a}}\right)$ Figure31 Electromagnetic TorqueOP4510 first we analyzed the results using software synchronized method and the results also analyzedon digital oscilloscope using hardware synchronized method.

Due to DTC method errors between estimated and actual values of flux and torque, it is possible to control directly different state of inverter to reduce torque and flux errors. The simulated results help to determined precise control of estimated torque and hence it leads to reduction in less steady state errors compared with other conventional methods of high performance motor drives. Also the real time simulation is performed using OPAL-RT. OP4510 first we analyzed the results using software synchronized method, and the results also analyzed on digital oscilloscope using hardware synchronized method.

\section{V. . REFERENCES}

[1] J. R. Hendershort, Jr. and T. J. E. Miller, "Design of Brushless Permanent- Magnet Machines”. Venice, FL, USA: Motor Design Books, 2010.

[2] Pragasen Pillay and Krishnan.R, "Modeling, Simulation and Analysis of Permanent- Magnet Motor Drives, Part I: The Permanent-Magnet Synchronous Motor Drive," IEEE Trans. Ind. Appl., vol. 25, no. 2, pp. 265-273, Apr. 1989.

[3] F. Bodin and S. Siala, "New Reference Frame for Brushless DC Motor Drive”, in Proc. IEEE PEVD Annu. Meeting, London, U.K., pp. 554-559, Sep. 21-23, 1998.

[4] D. Grenier, L. A. Dessaint, O. Akhrif, and J. P. Louis, "A parklike transformation for the study and the control of a nonsinusoidal brushless de motor," in Proc. IEEE IECON, Orlando, FL, USA, Nov. 6-10, 1995, vol. 2, pp. 836-843

[5] B. K. Lee, T. H. Kim, and M. Ehsani, "On the feasibility of fourswitch three phase BLDC motor drives for low cost commercial applications: Topology and control," IEEE Trans. Power. Electron., vol. 18, no. 1, pp. 164-172, Jan. 2003.

[6] S. B. Ozturk, W. C. Alexander, and H. A. Toliyat, "Direct Torque and Indirect Flux Control of Brushless DC Motor,"IEEE/ASME TRANSACTIONS ON MECHATRONICS, VOL. 16, NO. 2, APRIL 2011.

[7] S. B. Ozturk, W. C. Alexander, and H. A. Toliyat, "Direct torque control of four-switch brushless de motor with non-sinusoidal back EMF," IEEE Trans. Power Electron., vol. 25, no. 2, pp. 263-271, Feb. 2010.

[8] B.K.Bose, "Power electronics and AC drives, IEEE Press, New York, 1996.

[9] Mourad Masmoudi, Bassem El Badsi, and Ahmed Masmoudi, "Direct Torque Control of Brushless DC Motor Drives with Improved Reliability" IEEE TRANSACTIONS ON INDUSTRY APPLICATIONS 